\title{
Turnip aphids (Lipaphis erysimi) discriminate host plants based on the strain of Cauliflower mosaic virus infection
}

\author{
Mustafa Adhab ${ }^{1,2 *}$, Deborah Finke ${ }^{1}$, James Schoelz ${ }^{1}$ \\ ${ }^{1}$ Division of Plant Sciences, University of Missouri, Columbia, MO 65211, ${ }^{2}$ Plant Protection Department, University of Baghdad, Baghdad, Iraq 10071
}

\section{A B S T R A C T}

\begin{abstract}
The degree of vector preference for virus-infected plants can alter the progress of virus epidemics. The objective of this study is to test whether infection of turnip plants with different strains of Cauliflower mosaic virus (CaMV) can influence the feeding preference of the turnip aphid (Lipaphis erysimi). Three different strains of CaMV that cause different types of symptoms on turnips were used in this study. These strains were NY8153 (severe, causes necrosis of the midrib and mottling with severe stunting), W260 (mild, causes mosaic with moderate stunting) and $\mathrm{H} 12$ (symptomless). Results showed that turnip aphids preferred W260-infected plants, in general. When given a choice, aphids chose W260-infected plants significantly more often than NY8153-infected or healthy plants. W260-infected vs. H12infected plants showed a trend in the same direction. Also, aphids chose plants infected with $\mathrm{H} 12$ more often than healthy plants when given a choice. By contrast, turnip aphids showed no preference between NY8153-infected and healthy plants, or between NY8153infected and $\mathrm{H} 12$-infected plants. Therefore, we conclude that aphids can recognize plants infected with different strains of CaMV and will choose plants with specific strains over others. Specifically, aphids prefer W260-infected turnips over other choices. These results suggest that virus infection affects the aphid host choice and this may have implications for the spread of different virus strains.
\end{abstract}

Keywords: Aphid host preference; Aphid-host interaction; Plant virus dispersal; Virus-vector relationship; Virus strains

\section{INTRODUCTION}

Host plant traits can be altered by an attack of vector-borne pathogens, and this plant response affects the community of organisms in the host plant as well as the vectoring insects (Eigenbrode et al., 2002; Kersch-Becker and Thaler, 2014; Mauck et al., 2010, 2012; Stout et al., 2006). For example, the suitability of host plants for aphid vectors can be altered by plant virus infection (Kersch-Becker and Thaler, 2014). Many studies indicate that virus-infected plants are more preferable than virus-free plants with respect to the growth rates, longevity and reproduction of the vector (Blua et al., 1994; Fereres et al., 1999; Jiménez-Martínez et al., 2004; Srinivasan et al., 2008).

Vector behavior is shaped by natural selection in response to virus-induced changes in host plant traits (Eigenbrode et al., 2002). The virus and the vector are potentially linked in a mutualistic interaction if improved vector performance on virus-infected plants also enhances the spread of the virus. Different viruses alter plant traits and affect their vector species differently (Belliure et al., 2005, 2008; Eigenbrode et al., 2002; Hodge and Powell, 2008). Some viruses produce symptoms on their infected host plants that can be considered as mechanisms by which the virus manipulates its vector through the host plant (Belliure et al., 2005, 2008; Hodge and Powell, 2008; Musser et al., 2003). For example, it has been shown that Barley yellow dwarf virus on wheat and Potato leafroll virus infecting potato induce changes in the host selection behavior of their aphid vector indirectly (Eigenbrode et al., 2002; Jiménez-Martínez et al., 2004). Many studies have reported that plants infected with these viruses change volatile organic compound profiles that elicit better settling of their non-infective vectors (Eigenbrode et al., 2002; Jiménez-Martínez et al., 2004).

The mechanism of viral transmission in many cases determines the way that the virus alters the host and manipulates its vector. Persistently transmitted viruses, 


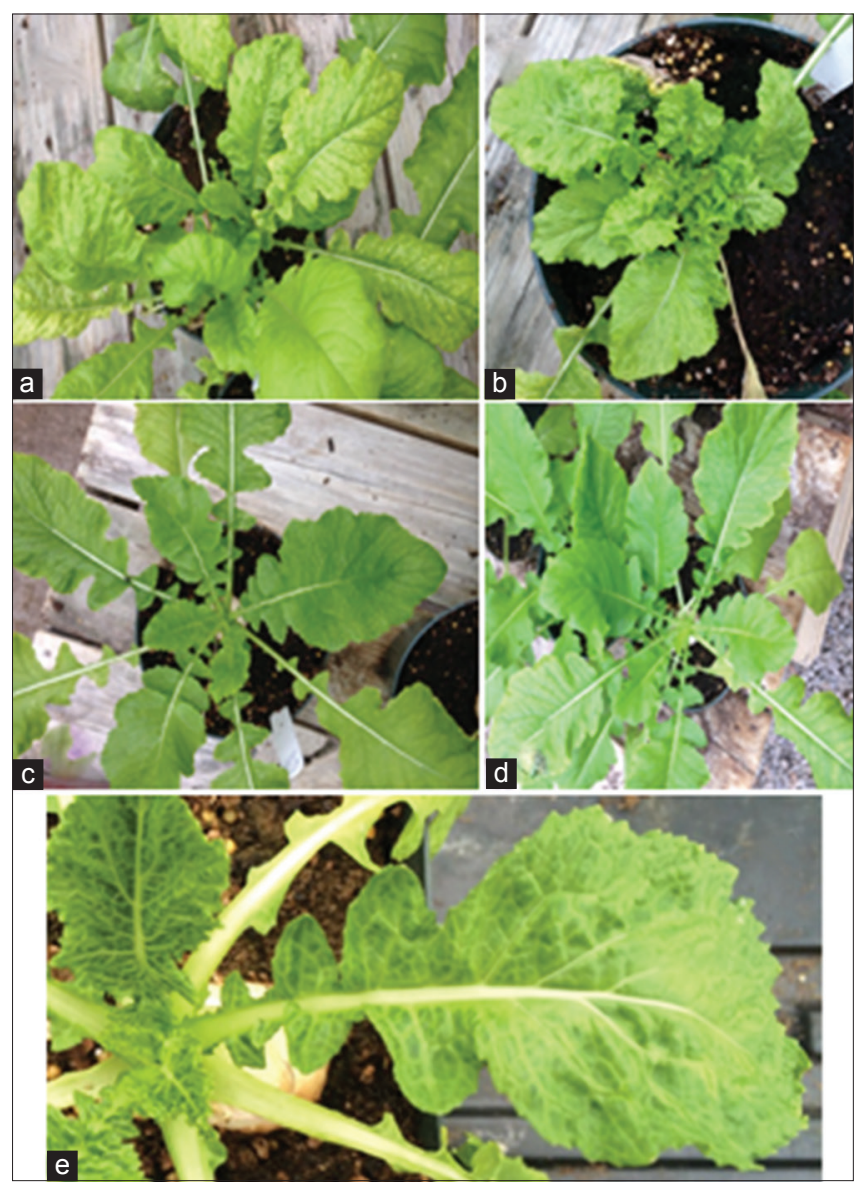

Fig 1. Characteristic symptoms of turnip plants infected with different CaMV strains, including (a) W260-infected plant, (b) NY8153-infected plants, (c) H12-infected plant, compared to (d) healthy plant. (e) Mosaic symptoms on turnip leaves infected with CaMV strain W260.

both circulative (e.g., Beet western yellows polerovirus) and propagative (e.g., Maize mosaic Rhabdovirus), are acquired by their vector in a period of hours and have a retention time equal to the life of the vector; these viruses circulate through the vector to ultimately reach the salivary glands, from which they can be transmitted to other organisms (Sylvester, 1980; Ng and Falk, 2006; Mauck et al., 2012). Non-persistently transmitted viruses (also known as styletborne) require only seconds to a few minutes for acquisition and, generally, the retention of the virus is for no more than a few minutes to hours. The virions of non-persistent viruses, such as Tobacco etch potyvirus, bind to the aphid stylet without replication within the aphid vector $(\mathrm{Ng}$ and Falk, 2006). On the other hand, semi-persistent viruses, such as Cauliflower mosaic virus (CaMV) (Caulimovirus), are acquired by their vectors following a feeding period of minutes to several hours and have a retention time of several hours to a few days (Ng and Falk, 2006). CaMV virions also bind to the stylet within a unique region called the "acrostyle" (Uzest et al., 2010). It has been predicted that persistent and semi-persistent viruses attract vectors and encourage their long-term feeding by promoting plant quality (Alvarez et al., 2007; Eigenbrode et al., 2002; Jiu et al., 2007; Mauck et al., 2012). On the other hand, nonpersistent viruses will produce signals that are attractive to vectors, but reduce host plant quality to encourage vector dispersal following short bouts of feeding, since this kind of virus is rapidly acquired by the vector and can be immediately transmitted to other plants (Mauck et al., 2010, 2012).

In this study, we test the preference of the turnip aphid (Lipaphis erysimi (Kaltenbach)) for turnip host plants (Brassica rapa L. var. rapa "Just Right") infected with three different strains of CaMV. The three CaMV strains (W260, NY8153 and H12) used in this study infect turnips with different levels of symptoms. The mild strain W260 causes mosaic with moderate stunting (Anderson et al., 1991), while the severe strain NY8153 causes necrosis of the midrib and mottling with severe stunting (Melcher, 1989), whereas H12 is nearly symptomless (Fig. 1)(Daubert et al., 1984; Schoelz et al., 1986). All three strains of CaMV are transmitted by the turnip aphid in a semi-persistent manner, but they impact the host plant differently. We hypothesized that different CaMV strains will alter the host plant choice of turnip aphids by altering plant traits.

\section{MATERIALS AND METHODS}

\section{Plant growth conditions}

Turnip plants (Brassica rapa L. var. rapa "Just Right") used in these experiments were grown from seeds in $10 \mathrm{~cm}$ pots in a greenhouse $\left(20^{\circ} \mathrm{C}\right.$ temperature and $60 \%$ humidity) and reared for three weeks before being inoculated with the virus. Plants were planted in commercial potting soil (GROWING MIX 1-P, professional formula, Fafard ${ }^{\mathbb{B}}$ ), watered daily and received one treatment of fertilizer (Osmocote ${ }^{\circledR}$ water-soluble fertilizer) at approximately two weeks after emerging.

\section{Turnip aphids}

Turnip aphids (L. erysimi (Kaltenbach)) were collected from Brassica oleracea 'Kale Redbor' plants located at the University of Missouri - Columbia campus, identified to species (Adhab and Schoelz, 2015) and reared on uninfected turnip plants in the greenhouse $\left(25 \pm 2^{\circ} \mathrm{C}\right.$ and 16:8 of Light: Dark cycle) prior to experiments.

\section{Virus strains and inoculation}

CaMV strains W260, NY8153 and H12 were used (Anderson et al., 1991; Melcher 1989; Daubert et al., 1984; Schoelz et al., 1986) for the aphid choice tests. H12 is a nearly symptomless chimeric virus constructed through recombinant DNA techniques to identify CaMV genes that contribute to CaMV host range and symptomatology (Schoelz et al., 1986). Infections were initiated from dried 


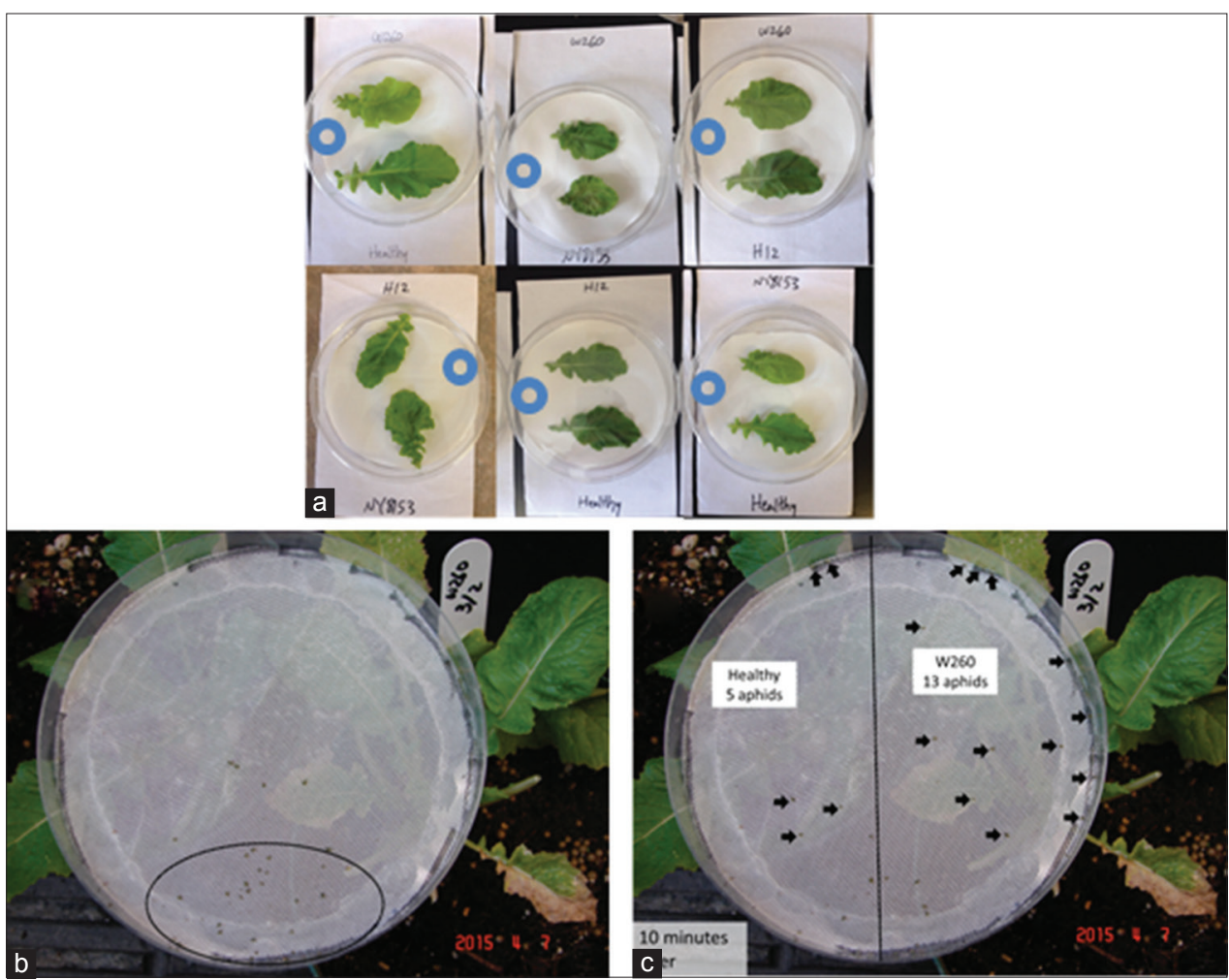

Fig 2. The design of the choice experiments for detached leaves and at the whole plant level. (a) The arrangement of leaves in petri plates. The blue circle illustrates the spot where the aphids released in each plate. (b) The design of the whole plant test. A plate with a mesh base was placed above two plants. The aphids released in a distance on the mesh. (c) Aphids distribution 10 minutes after release.

turnip tissue infected with each of the strains. Turnip plants were mechanically inoculated with inoculum consisting of triturated leaf material from CaMV-infected turnip plants in phosphate buffer $(50 \mathrm{mM}, \mathrm{pH}$ 7). Inoculum was individually applied to turnip plants dusted with carborundum by rubbing the entire upper leaf surface. H12 infections could be confirmed because the virus initially induces a very mild mosaic that eventually disappears over time. All inoculations were done in the greenhouse at $20^{\circ} \mathrm{C}$ temperature and $60 \%$ humidity.

\section{Choice experiments: Detached leaf assay under daylight conditions}

This experiment was conducted in the lab using 150 $\times 20 \mathrm{~mm}$ Petri dishes (Stackable Lid; FisherScientific, Pittsburgh, PA). Ten mature females were offered two leaves, which were cut at the petiole. The group of ten females was placed on a filter paper at the edge of the dish with a pair of leaves that were an equal distance from the aphids (Fig. 2A). Combinations between treatments were Healthy leaf $\times$ W260-infected leaf, Healthy leaf $\times$ NY815- infected leaf, Healthy leaf $\times$ H12-infected leaf, W260-infected leaf $\times$ NY8153-infected leaf, W260infected leaf $\times$ H12-infected leaf and NY8153-infected leaf $\times$ H12-infected leaf.
A different group of aphids was used for each replicate, and fresh leaves were used in each replication. The side on which particular treatments were offered was alternated with each replication. Seven replications were conducted for each treatment. The number of aphids on each of the two leaves was counted after one hour.

\section{Whole plant assay under low light conditions}

Twenty mature females of L. erysimi were released at a time on a modified $150 \times 20 \mathrm{~mm}$ Petri dish that had its base replaced with mesh to allow the free flow of volatiles from plants into the dish (Fig. 2B). The Petri dish was suspended $1 \mathrm{~cm}$ above two treatment plants; the two treatments were either turnip plants infected with different CaMV strains or a healthy plant vs CaMV-infected plant. The distance between each pair of plants was about $5 \mathrm{~cm}$. Paired choice treatment combinations were Healthy plant $\times$ W260infected, Healthy $\times$ NY815-infected and W260-infected $\times$ NY8153-infected plants. The Petri dishes were arranged such that half of the dish was over one plant treatment and the other half over the other plant. The side on which particular treatments were offered was alternated with each replication. Aphids were subjected to a 1 hour starvation period before being placed on the dish. Aphids were released at the edge of the dish, equidistant from both plants, and the number of individuals that moved in 


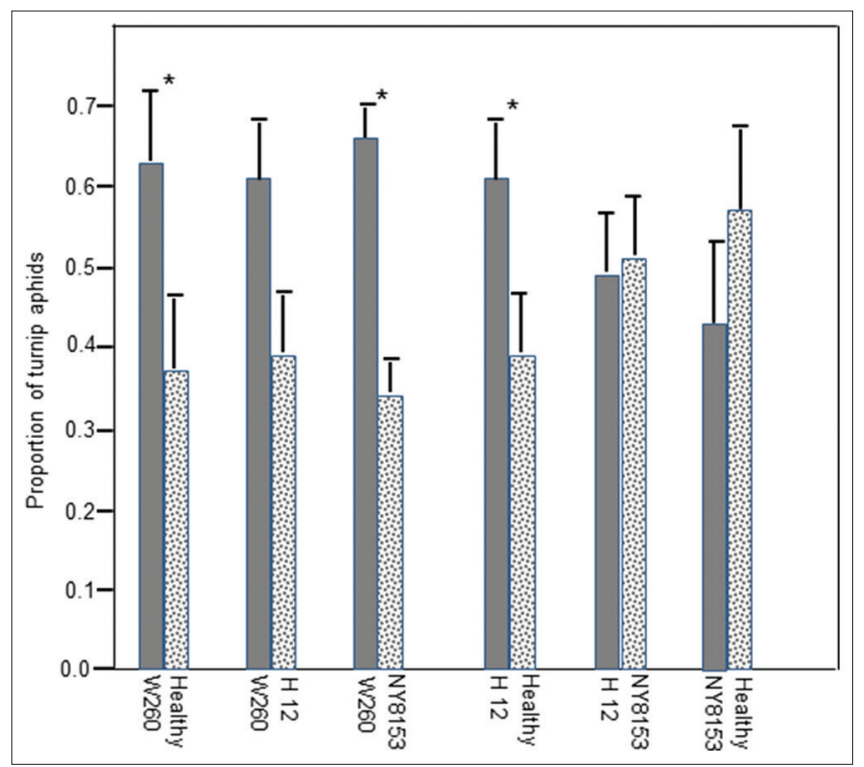

Fig 3. Proportions of turnip aphids (Lipaphis erysimi) choosing to colonize healthy turnip leaves or turnip leaves infected with a CaMV strain in pairwise choice tests. Three strains of CaMV were W260, NY8153 and H12. In this experiment, aphids were offered two leaves in a covered petri plate. Bars with an asterisk $\left(^{*}\right)$ are significantly different $(\mathrm{P}<0.05)$.

the direction of a particular treatment plant was counted 60 minutes after being released (Fig. 2B and 2C). Each paired choice treatment combination was repeated at least five times using a new group of aphids in each replication.

\section{Data analysis}

The proportion of the responding aphids that chose an inoculated or healthy plant was compared using Analysis of Variance (ANOVA) on logit transformed data to determine if there is any difference in host plant choice across treatments. SAS software (Version 9.4) was used to analyze data. Aphids that did not make a choice at the end of the time period were considered non-responsive and excluded from the analysis. Only aphids that made a choice were considered in the analysis.

\section{RESULTS}

\section{Turnip aphids prefer turnip leaves infected with certain strains of CaMV}

To investigate whether aphids could distinguish between infected and healthy plants, and among plants infected with different strains of CaMV, we offered aphids a pairwise choice between CaMV-infected leaves and healthy leaves in a petri plate where the aphids could come in contact with the leaves and feed on them. Turnip aphids tended to prefer CaMV-infected plants over healthy plants. However, this preference was strain-dependent. When given the choice in a petri dish assay between a detached turnip leaf from a W260-infected plant and a leaf from a healthy plant, aphids chose W260-infected leaves more often than healthy leaves $(F=5.91, \mathrm{P}=0.032)$. The same result was found between symptomless H12-infected plants and healthy plants, as aphids chose the symptomless H12-infected plants more often $(F=5.69, \mathrm{P}=0.035)$. We chose the $\mathrm{H} 12$ virus because previous studies had shown that turnips infected with this virus are virtually symptomless (Daubert et al., 1984; Schoelz et al., 1986). The observation that aphids chose H12infected plants over healthy plants suggests that aphids were not attracted by the chlorotic symptoms induced by W260, although we cannot rule out the possibility that aphids might be attracted to some alteration in color not perceived by the human eye. By contrast, no significant difference was recorded between NY8153-infected plants and healthy plants $(F=0.99, P=0.34)$ (Fig. 3; Supplemental Table 1).

When given a pairwise choice between turnip leaves infected with different CaMV strains, turnip aphids were also able to discriminate between CaMV strains. Aphids preferred leaves from W260-infected plants over leaves from NY8153-infected plants $(F=19.91, \mathrm{P}=0.001)$. Likewise, there was a trend for preference for W260infected over H12-infected plants $(F=2.59, \mathrm{P}=0.13)$. By contrast, aphids did not distinguish between $\mathrm{H} 12$-infected and NY8153-infected plants $(F=0.09, \mathrm{P}=0.78)$ (Fig. 3; Supplemental Table 1).

\section{Turnip aphids are attracted to turnip plants infected with CaMV strain W260}

To investigate whether turnip aphids are able to discriminate between CaMV-infected and healthy turnips and among plants infected with different strains of CaMV without being in contact with plants, we exposed aphids to two plants in pairwise choice tests. We placed aphids above the plants in a modified petri plate with a mesh base under low light conditions, so aphids could sense plant volatiles, but could not touch or feed upon plants. Aphids responded differently to turnips infected with different CaMV strains. Turnip aphids always preferred turnip plants infected with CaMV strain W260 (Fig. 4; Supplemental Table 2). Aphids preferred W260-infected plants over NY8153-infected plants $(F=45$, $\mathrm{P}=0.0026)$ and as with the detached leaf assay, when given a choice between W260-infected turnips and healthy turnip plants, aphids chose W260-infected more often $(F=22.04$, P $=0.0093)$. The opposite was true when aphids were offered turnip plants infected with NY8153; aphids preferred healthy plants when given a choice between NY8153-infected and healthy plants $(F=111.52, \mathrm{P}=0.0005)$.

\section{DISCUSSION}

Plant viruses can have indirect effects on their vectors by altering the biochemistry of their plant hosts, which 


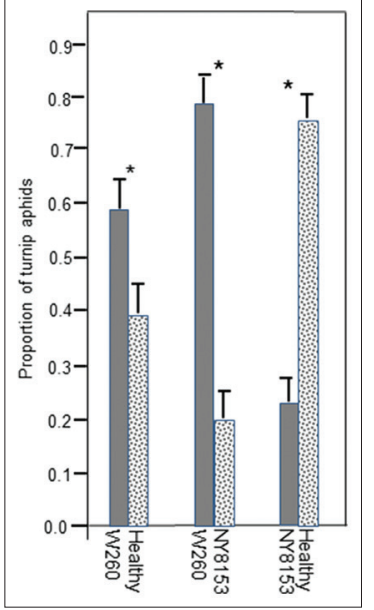

Fig 4. Proportion of turnip aphids (Lipaphis erysimi) choosing healthy turnip plants or plants infected with a CaMV strain when offered the whole plant. The two strains of CaMV used were W260 and NY8153. Bars with an asterisk $\left({ }^{*}\right)$ are significantly different $(P<0.05)$.

provokes changes in the behavior or performance of the vector (Hodge and Powell, 2008, Jiu et al., 2007). It has been hypothesized that viruses alter plant quality to influence vector dispersal and consequently enhance virus spread (Mauck et al., 2010). For non-persistent virus pathogens, specifically, it is thought that viruses induce changes in the host plant to attract vectors; however it is also possible that host plant quality will be decreased (Mauck et al., 2010, 2012).

We predicted that when CaMV strains infect turnips, they would alter the vector's choice of host plant. Our study shows, for the first time, that turnip aphids prefer turnips that are infected with some strains of CaMV over healthy plants and also discriminate among plants infected with different CaMV strains. In the detached leaf assay, we offered aphids a choice from two leaves in the same plate, in which the aphids could see, reach and feed on the leaf they prefer. We found that aphids consistently chose leaves from W260-infected turnips or H12-infected turnips more frequently than leaves from healthy plants. Aphids, however, did not prefer plants infected with CaMV strain NY8153. The fact that aphids chose symptomless H12-infected leaves over healthy leaves in the petri dish assay suggests that volatiles or some other change in plant quality attracted the aphids, rather than some visual cue such as a change in color. Also, the fact that aphids chose healthy leaves over NY8153-infected leaves in the whole plant assay (Fig. 3) and could not discriminate between healthy and NY8153infected leaves in the detached leaf assay (Fig. 1) further suggests that aphids were not attracted to a color in the CaMV-infected leaves or some other visual cue. The aphid preference for turnip leaves infected with W260 or H12 might reflect the activation of biochemical pathways in the plant that alter the perception of those plants by the aphid vectors (Kersch-Becker and Thaler, 2014; Kogovšek et al., 2010; Verbeek et al., 2010). These biochemical compounds might not be produced to the same level in NY8153 to preferentially attract aphids over healthy plants.

Some studies have been done to test the effect of volatiles produced by virus-infected plants on aphids. Eigenbrode et al., (2002) reported that Potato leafroll virus-infected potato plants release volatiles, and consequently, they are preferred by $M$. persicae more than healthy plants or even more than Potato virus $\mathrm{X}$-infected or Potato virus Y-infected plants (Eigenbrode et al., 2002). Other studies stated that infection by plant viruses increases the amount of carbohydrates and amino acids in leaves, and as a result, increase the arrestment and reproduction of the vectors on virus-infected plants, which eventually increase the rate of virus transmission through its aphid vector (Casteel et al., 2014; Castle and Berger, 1993; Srinivasan and Alvarez, 2007).

\section{CONCLUSIONS}

Our results show that the responses of turnip aphids varied for different strains of CaMV, suggesting that turnip aphids can discriminate between different strains of CaMV and can prefer one over the other. Further research will be necessary to examine the profiles of volatiles from turnips to see what types of compounds might attract aphids to CaMV-infected plants.

\section{ACKNOWLEDGEMENTS}

Mustafa Adhab would like to thank The Higher Committee of Education Development in Iraq (HCED) for being his scholarship sponsor and the Milliken Endowment at the University of Missouri for additional support. We also thank. Hussein Almtarfi and Sulaiman Ali from the Division of Plant Sciences, University of Missouri-Columbia for their help in the data analysis.

\section{Authors' contributions}

M.A. conducted the experiments. M.A., D. F. and J.S designed the experiments. M.A. prepared the draft manuscript. D.F. and M.A. analyzed the data. J.S. and D.F. revised the manuscript.

\section{REFERENCES}

Adhab, M. A. and J. E. Schoelz. 2015. Report of the turnip aphid, Lipaphis erysimi (Kaltenbach, 1843) from Missouri, USA. J. Plant Prot. Res. 55: 327-328.

Alvarez, A. E., E. Garzo, M. Verbeek, B. Vosman, M. Dicke and W. F. Tjallingii. 2007. Infection of potato plants with Potato leafroll virus changes attraction and feeding behaviour of Myzus persicae. Entomol. Exp. Appl. 125: 135-144. 
Anderson, E. J., S. G. Quu and J. E. Schoelz. 1991. Genetic analysis of determinants of disease severity and virus concentration in Cauliflower mosaic virus. Virology. 181: 647-655.

Belliure, B., A. Janssen, P. C. Maris, D. Peters and M. W. Sabelis. 2005s. Herbivore arthropods benefit from vectoring plant viruses. Ecol. Lett. 8: 70-79.

Belliure, B., A. Janssen and M. W. Sabelis. 2008. Herbivore benefits from vectoring plant virus through reduction of period of vulnerability to predation. Oecologia. 156: 797-806.

Blua, M. J., T. M. Perring and M. A. Madore. 1994. Plant virusinduced changes in aphid population development and temporal fluctuations in plant nutrients. J. Chem. Ecol. 20: 691-707.

Casteel, C. L., C. Yang, A. C. Nanduri, H. N. De Jong, S. A. Whitham and G. Jander. 2014. The Nla-Pro protein of Turnip mosaic virus improves growth and reproduction of the aphid vector, Myzus persicae (green peach aphid). Plant J. 77: 653-663.

Castle, S. and P. Berger. 1993. Rates of growth and increase of Myzus persicae on virus-infected potatoes according to type of virus-vector relationship. Entomol. Exp. Appl. 69: 51-60.

Daubert, S. D., J. Schoelz, L. Debao and R.J. Shepherd. 1984. Expression of disease symptoms in Cauliflower mosaic virus genomic hybrids. J. Mol. Appl. Genet. 2: 537-547.

Eigenbrode, S. D., H. Ding, P. Shiel and P. H. Berger. 2002. Volatiles from potato plants infected with Potato leafroll virus attract and arrest the virus vector, Myzus persicae (Homoptera: Aphididae). Proc. Royal Soc. Lond. 269: 455-460.

Fereres, A., G. Kampmeier and M. Irwin. 1999. Aphid attraction and preference for soybean and pepper plants infected with Potyviridae. Ann. Entomol. Soc. Am. 92: 542-548.

Hodge, S. and G. Powell. 2008. Do Plant viruses facilitate their aphid vectors by inducing symptoms that alter behavior and performance? Environ. Entomol. 37: 1573-1581.

Jiménez-Martínez, E., N. Bosque-Pérez, P. Berger and R. Zemetra. 2004. Life history of the bird cherry-oat aphid, Rhopalosiphum padi (Homoptera: Aphididae), on transgenic and untransformed wheat challenged with Barley yellow dwarf virus. J. Econ. Entomol. 97: 203-212.

Jiu, M., X. P. Zhou, L. Tong, J. Xu, X. Yang, F. H. Wan and S. S. Liu. 2007. Vector-virus mutualism accelerates population increase of an invasive whitefly. PLoS One. 2: e182.

Kersch-Becker, M.F. and J.S. Thaler. 2014. Virus strains differentially induce plant susceptibility to aphid vectors and chewing herbivores. Oecologia. 174: 883-892.

Kogovšek, P., M. Pompe-Novak, Š. Baebler, A. Rotter, L. Gow, K. Gruden,
G.D. Foster, N. Boonham and M. Ravnikar. 2010. Aggressive and mild Potato virus $\mathrm{Y}$ isolates trigger different specific responses in susceptible potato plants. Plant Pathol. 59: 1121-1132.

Mauck, K. E., C. M. De Moraes and M. C. Mescher. 2010. Deceptive chemical signals induced by a plant virus attract insect vectors to inferior hosts. Proc. Natl. Acad. Sci. 107: 3600-3605.

Mauck, K., N. A. Bosque-Pérez, S. D. Eigenbrode, C. M. De Moraes and M. C. Mescher. 2012. Transmission mechanisms shape pathogen effects on host-vector interactions: Evidence from plant viruses. Funct. Ecol. 26: 1162-1175.

Melcher, U. 1989. Symptoms of Cauliflower mosaic virus infection in Arabidopsis thaliana and turnip. Bot. Gaz. 150(2): 139-147.

Musser, R. O., S. M. Hum-Musser, G. W. Felton R. C. Gergerich. 2003. Increased larval growth and preference for virus-infected leaves by the Mexican bean beetle, Epilachna varivestis mulsant, a plant virus vector. J. Insect Behav. 16: 247-256.

$\mathrm{Ng}$, J. C. and B. W. Falk. 2006. Virus-vector interactions mediating nonpersistent and semipersistent transmission of plant viruses. Ann. Rev. Phytopathol. 44: 183-212.

Schoelz, J., R. J. Shepherd and S. Daubert. 1986. Region VI of Cauliflower mosaic virus encodes a host range determinant. Mol. Cell. Biol. 6: 2632-2637.

Srinivasan, R. and J. M. Alvarez. 2007. Effect of mixed viral infections (Potato virus Y-Potato leafroll virus) on biology and preference of vectors Myzus persicae and Macrosiphum euphorbiae (Hemiptera: Aphididae). J. Econ. Entomol. 100: 646-655.

Srinivasan, R., J. M. Alvarez, N. A. Bosque-Pérez, S. D. Eigenbrode and R.G. Novy. 2008. Effect of an alternate weed host, hairy nightshade, Solanum sarrachoides, on the biology of the two most important Potato leafroll virus (Luteoviridae: Polerovirus) vectors, Myzus persicae and Macrosiphum euphorbiae (Aphididae: Homoptera). Environ. Entomol. 37: 592-600.

Stout, M. J., J. S. Thaler and B. P. Thomma. 2006. Plant-mediated interactions between pathogenic microorganisms and herbivorous arthropods. Ann. Rev. Entomol. 51: 663-689.

Sylvester, E. S. 1980. Circulative and propagative virus transmission by aphids. Ann. Rev. Entomol. 25: 257-286.

Uzest, M., D. Gargani, A. Dombrovsky, C. Cazevieillec, D. Cot and S. Blanc. 2010. The "acrostyle": A newly described anatomical structure in aphid stylets. Arthropod Struct Dev 39: 221-229.

Verbeek, M., P. G. M. Piron, A. M. Dullemans, C. Cuperus, R. A. A. Van Der Vlugt. 2010. Determination of aphid transmission efficiencies for N, NTN and Wilga strains of Potato virus Y. Ann. Appl. Biol. 156: 39-49. 
Supplemental Table 1: Proportions of the choices that turnip aphids made in each replication of different treatments in choice experiment under detached leaves level with the statistical analysis of each treatment. The numbers in the table are the proportion of turnip aphids that chose one of the two treatments, with the proportions separated by a colon

\begin{tabular}{lccccccccccc}
\hline Treatment & Rep1 & Rep2 & Rep3 & Rep4 & Rep5 & Rep6 & Rep7 & LS means & F value & Pr $>$ F & Std error \\
\hline W260 vs healthy* & $0.8: 0.2$ & $0.8: 0.2$ & $0.6: 0.4$ & $0.8: 0.2$ & $0.3: 0.7$ & $0.5: 0.5$ & $0.6: 0.4$ & $0.63: 0.37$ & 5.91 & 0.0316 & \pm 0.07 \\
W260 vs H12 & $0.4: 0.6$ & $0.5: 0.5$ & $0.3: 0.7$ & $0.9: 0.1$ & $0.9: 0.1$ & $0.7: 0.3$ & $0.6: 0.4$ & $0.61: 0.39$ & 2.59 & 0.1332 & \pm 0.09 \\
W260 vs NY8153* & $0.6: 0.4$ & $0.5: 0.5$ & $0.8: 0.2$ & $0.7: 0.3$ & $0.6: 0.4$ & $0.6: 0.4$ & $0.8: 0.2$ & $0.66: 0.34$ & 19.91 & 0.0008 & \pm 0.04 \\
H12 vs healthy* & $0.6: 0.4$ & $0.7: 0.3$ & $0.7: 0.3$ & $0.8: 0.2$ & $0.7: 0.3$ & $0.6: 0.4$ & $0.2: 0.8$ & $0.61: 0.39$ & 5.69 & 0.0345 & \pm 0.07 \\
H12 vs NY8153 & $0.6: 0.3$ & $0.5: 0.5$ & $0.6: 0.4$ & $0.6: 0.4$ & $0.5: 0.5$ & $0.5: 0.5$ & $0.1: 0.9$ & $0.49: 0.51$ & 0.09 & 0.7753 & \pm 0.07 \\
NY8153 vs healthy & $0.4: 0.5$ & $0.1: 0.9$ & $0.3: 0.7$ & $0.7: 0.3$ & $0.7: 0.3$ & $0.1: 0.9$ & $0.7: 0.3$ & $0.43: 0.57$ & 0.99 & 0.3398 & \pm 0.10 \\
\hline
\end{tabular}

Supplementary Table 2: Proportions of the choices that turnip aphids made in each replication of different treatments in choice experiment under whole plant level with the statistical analysis of each treatment. The numbers in the table are the proportion of turnip aphids that chose one of the two treatments, with the proportions separated by a colon

\begin{tabular}{lcccccccrr}
\hline Treatment & Rep1 & Rep2 & Rep3 & Rep4 & Rep5 & LS mean & F value & Pr $>$ F & Std error \\
& & & & & & & & \\
W260 vs healthy* & $0.6: 0.4$ & $0.7: 0.3$ & $0.7: 0.3$ & $0.75: 0.25$ & $0.9: 0.1$ & $0.73: 0.27$ & 22.04 & 0.0093 & \pm 0.05 \\
W260 vs NY8153* $^{*}$ & $0.8: 0.2$ & $0.9: 0.1$ & $0.7: 0.3$ & $0.7: 0.3$ & $0.9: 0.1$ & $0.8: 0.2$ & 45 & 0.0026 & \pm 0.045 \\
NY8153 vs healthy* $^{*}$ & $0.23: 0.77$ & $0.12: 0.88$ & $0.0: 1.0$ & $0.12: 0.88$ & $0.1: 0.9$ & $0.114: 0.886$ & 111.52 & 0.0005 & \pm 0.04 \\
\hline
\end{tabular}

